Volume 10, Nomor 2, November 2018, pp 212-222 Copyright (C) 2017 Jurnal Akuntansi Maranatha, Program Studi Akuntansi, Fakultas Ekonomi,

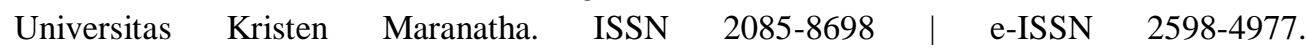
http://journal.maranatha.edu

\title{
Pengaruh Partisipasi Karyawan Terhadap Kinerja Keselamatan dan Kesehatan Kerja Rumah Sakit (K3RS) Santo Borromeus
}

\author{
Tanti Winarti \\ Sekolah Pascasarjana UNPAR, Bandung, 40117, Jawa Barat, Indonesia \\ tantiwinarti@gmail.com \\ Banowati Talim \\ Sekolah Pascasarjana UNPAR, Bandung, 40117, Jawa Barat, Indonesia
}

\begin{abstract}
Occupational safety and health is an effort to provide safety assurance and improve the health of workers by prevention of occupational accidents and diseases, hazards in the workplace, health promotion, treatment and rehabilitation. Hospitals have a variety of potential hazards, therefore Hospital is required to implement safety and health efforts through the implementation of safety and health management work carried out in an integrated and comprehensive. Employee participation is an important factor in improving safety and health performance.This study aims to determine and analyze the extent of the influence of employee participation on the performance of occupational safety and health of Hospital Santo Borromeus. This type of research is a survey study, supported by the spread of questionnaires as a means of data collection. The research method used is a mix method with descriptive analysis technique. Other research data were obtained from interviews, observations, and document studies. This study was restricted to the Laboratory unit and the Central Sterilization Supply Department (CSSD) unit of Santo Borromeus Hospital. The results showed that employee participation has a significant influence on the performance of occupational safety and health of Santo Borromeus Hospital with total influence of $31.2 \%$. And based on the result of correlation analysis, the type of work accident has a significant influence on job position, this is proved by significance value $<0,05$.
\end{abstract}

Keywords: Employee Participation, Occupational Health and Safety Hospital, Occupational Types

\section{Pendahuluan}

Setiap tahun jumlah penduduk Negara Indonesia semakin meningkat, menurut data BPS jumlah penduduk Indonesia hingga Juni 2017 mencapai 261 juta jiwa yang mana sebagian besar berasal dari kelompok usia produktif (15 hingga 64 tahun). Dalam hal ini, pertumbuhan jumlah penduduk berpengaruh terhadap peningkatan jumlah angkatan kerja yang juga diikuti oleh peningkatan angkatan kerja yang bekerja. 
Hal tersebut di dukung oleh data BPS yang menunjukkan bahwa perkembangan angkatan kerja Indonesia hingga tahun 2017 mencapai 131,544,111 jiwa, dimana jumlah tersebut jauh lebih besar jika dibandingkan dari tahun-tahun sebelumnya.

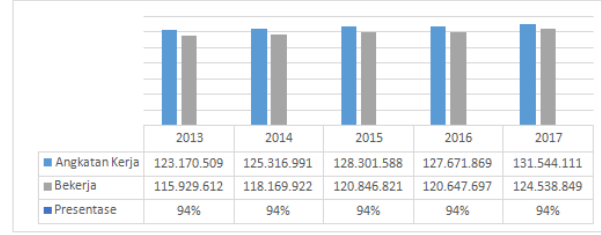

\section{Grafik Perkembangan Angkatan Kerja Indonesia Tahun 2013-2017 Sumber: Badan Pusat Statistik 2017}

Pada gambar diatas menunjukkan bahwa presentase angkatan kerja yang bekerja setiap tahunnya mencapai $94 \%$. Pada tahun 2017, peningkatan angkatan kerja yang bekerja mencapai $0,03 \%$ dari tahun 2016. Berdasarkan banyaknya angkatan kerja yang bekerja, menunjukkan bahwa diperlukan adanya program kesejahteraan karyawan yang dapat mendukung produktivitas kinerja. Kesejahteraan karyawan tidak hanya dapat diberikan dalam bentuk materi seperti tunjangan dan kompensasi, tetapi juga dapat diberikan dalam bentuk non materi seperti kenyamanan dan keamanan saat bekerja. Dalam hal ini, perusahaan dapat memperhatikan kesejahteraan karyawan dalam bentuk non materi salah satunya melalui penerapan keselamatan dan kesehatan kerja sesuai dengan Pasal 86 UU Ketenagakerjaan N0. 13 Tahun 2003, bahwa:

"Setiap pekerja/buruh mempunyai hak untuk memperoleh perlindungan atas: $a$. keselamatan dan kesehatan kerja; $b$. moral dan kesusilaan; dan c. perlakuan yang sesuai dengan harkat dan martabat manusia serta nilai-nilai agama. Dan untuk melindungi keselamatan pekerja/buruh guna mewujudkan produktivitas kerja yang optimal diselenggarakan upaya keselamatan dan kesehatan kerja".

Keselamatan dan kesehatan kerja merupakan segala bentuk kegiatan untuk menjamin dan melindungi keselamatan dan kesehatan karyawan melalui upaya pencegahan kecelakaan kerja dan penyakit akibat pekerjaan. Keselamatan dan kesehatan kerja adalah suatu program yang dibuat bagi karyawan maupun pengusaha dengan cara mengenali hal-hal yang berpotensi menimbulkan kecelakaan kerja dan penyakit akibat hubungan kerja melalui tindakan antisispatif.

Undang-Undang Nomor 36 Tahun 2009 Pasal 164 tentang Kesehatan, menyatakan bahwa upaya keselamatan dan kesehatan kerja harus diselenggarakan di semua tempat kerja baik sektor formal maupun informal yang mempunyai risiko bahaya kecelakaan kerja dan gangguan kesehatan akibat pekerjaan. Dalam hal ini, Rumah Sakit termasuk kedalam sektor formal yang mempunyai berbagai potensi bahaya. Selain potensi bahaya penularan penyakit, potensi bahaya lain yang ada dalam lingkungan Rumah Sakit yaitu kecelakaan yang diakibatkan oleh ledakan, kebakaran, kecelakaan yang berhubungan dengan instalasi listrik, radiasi, bahan kimia berbahaya, gas-gas anastesi, gangguan psikososial dan ergonomi. Semua potensi bahaya tersebut di atas, jelas mengancam keselamatan dan kesehatan yang tidak hanya berdampak terhadap para karyawan Rumah Sakit, tetapi juga berdampak terhadap pasien maupun pengunjung/ pengantar pasien.

Keselamatan dan kesehatan kerja bagi karyawan Rumah Sakit atau dapat disebut sebagai tenaga kesehatan, telah diatur dalam Undang-Undang Nomor 36 Tahun 2014 Pasal 57 bag. (d) tentang Tenaga Kesehatan yang menyatakan bahwa "tenaga kesehatan dalam menjalankan praktik berhak memperoleh pelindungan atas keselamatan dan kesehatan kerja". Oleh karena itu, Rumah Sakit dituntut untuk melaksanakan upaya keselamatan dan 
kesehatan kerja melalui penerapan manajemen keselamatan dan kesehatan kerja yang dilaksanakan secara terintegrasi dan menyeluruh, sehingga risiko terjadinya kecelakaan kerja dan penyakit akibat pekerjaan di Rumah Sakit dapat dihindari.

Implementasi keselamatan dan kesehatan kerja yang efektif bergantung pada faktor manusia itu sendiri (Tint, 2006 dan Zubbar, 2014). Dengan kata lain, partisipasi karyawan merupakan faktor penting dalam meningkatkan kinerja keselamatan dan kesehatan kerja. Kinerja keselamatan dan kesehatan kerja yang efektif dapat dilakukan melalu partisispasi karyawan terkait kesadaran karyawan akan pentingnya keselamatan dan kesehatan di tempat kerja (Smith, 1994; Tint, 2006; Serrette, 2001; Lyon, 2005; Akpan, 2011; Zubbar, 2014). Serta mematuhi setiap peraturan dan kebijakan terkait keselamatan dan kesehatan kerja yang telah ditetapkan. Sehingga implementasi keselamatan dan kesehatam kerja dapat berjalan dengan efektif. Oleh karena itu peneliti bermaksud untuk melakukan penelitian mengenai bagaimana pengaruh partisipasi karyawan terhadap kinerja keselamatan dan kesehatan kerja di Rumah Sakit (K3RS) Santo Borromeus.

\section{Identifikasi Masalah}

1. Apakah partisipasi karyawan berpengaruh terhadap kinerja keselamatan dan kesehatan kerja Rumah Sakit (K3RS) Santo Borromeus?

2. Apakah jenis kecelakaan kerja berpengaruh terhadap posisi jabatan karyawan Rumah Sakit Santo Borromeus?

\section{Tujuan Penelitian}

1. Untuk menguji dan menganalisis seberapa besar pengaruh partisispasi karyawan terhadap kinerja keselamatan dan kesehatan kerja Rumah Sakit (K3RS) Santo Borromeus.

2. Untuk menguji dan menganalisis signifikansi pengaruh jenis kecelakaan kerja terhadap posisi jabatan karyawan Rumah Sakit (K3RS) Santo Borromeus.

\section{Kerangka Teoritis dan Hipotesis}

Sumber daya manusia merupakan faktor strategis dalam semua kegiatan organisasi, dimana sumber daya manusia memiliki peran penting dalam mencapai tujuan dan sasaran organisasi.

\section{Teori Partisipasi Karyawan}

Partisipasi adalah berbagai bentuk peran serta anggota organisasi dalam menggunakan tenaga dan pikiran serta waktunya dalam mewujudkan tujuan organisasi (Hasibuan, 2005). Partisipasi adalah tanggungjawab karyawan yang didasari pada kesadaran penuh dalam mentaati dan mematuhi serta mengerjakan semua tugas pekerjaannya dengan baik (Malthis \& Jackson, 2002).

Partisipasi karyawan adalah dimana karyawan dalam suatu organisasi memainkan peran lebih besar dalam proses pengambilan keputusan. Bahwa karyawan diberikan kesempatan untuk mempengaruhi keputusan manajemen dan dapat berkontribusi pada peningkatan kinerja organisasi (Amstrong, 2006).

Berdasarkan beberapa definisi diatas, dapat disimpulkan bahwa partisipasi karyawan merupakan bentuk peran serta karyawan dalam menggunakan tenaga dan pikiran serta waktunya dalam mewujudkan tujuan organisasi yang didasari pada kesadaran penuh dalam mentaati dan mematuhi serta mengerjakan semua tugas pekerjaannya dengan baik.

Partisipasi karyawan memiliki tiga gagasan penting yaitu (Dewi, 2006):

1. Keterlibatan mental dan emosional/inisiatif

Pertama dan yang paling utama, partisipasi berarti keterlibatan mental dan emosional daripada hanya berupa aktivitas fisik. Karyawan yang 
berpartisipasi melibatkan emosionalnya seperti menyampaikan pendapat daripada hanya terlibat dalam penyelesaian tugas sesuai tenggat waktu.

2. Motivasi kontribusi

Dalam partisipasi, penting untuk memotivasi karyawan yang memberikan kontribusi. Mereka diberi kesempatan untuk menyalurkan sumber inisiatif dan kreativitasnya untuk mencapai tujuan organisasi. Partisipasi dapat meningkatkan motivasi dan membantu karyawan untuk memahami tujuan organisasi.

3. Tanggungjawab

Partisipasi mendorong karyawan untuk menerima tanggung jawab dalam aktivitas kelompok. Hal tersebut merupakan proses sosial agar karyawan dapat terlibat langsung dalam semua kegiatan organisasi sehingga memunculkan kesediaan untuk dapat mewujudkan keberhasilan organisasi.

Partisipasi karyawan mendorong keterlibatan aktif karyawan untuk berkontribusi dalam pencapaian tujuan perusahaan. Dalam hal ini, partisipasi karyawan sangat berpengaruh terhadap efektivitas keselamatan dan kesehatan kerja. Dimana efektivitas keselamatan dan kesehatan kerja dapat dilakukan melalui bentuk keterlibatan karyawan dengan mematuhi setiap peraturan terkait keselamatan dan kesehatan kerja serta secara sadar selalu menggunakan alat pelindung diri (APD). Hal tersebut sesuai dengan Pasal 13 Undang-Undang No. 1 Tahun 1970 tentang Keselamatan Kerja, bahwa:

"Barangsiapa akan memasuki sesuatu tempat kerja, diwajibkan menaati semua petunjuk keselamatan kerja dan memakai alat-alat perlindungan diri yang diwajibkan".

Partisipasi karyawan juga tidak terlepas dari peran pemimpin yang berkomitmen terhadap Keselamatan dan Kesehatan Kerja karyawan. Menurut Mullen, pemimpin yang menunjukkan komitmen terhadap Keselamatan dan Kesehatan Kerja karyawan dengan secara aktif memberikan keyakinan dan arahan mengenai Keselamatan dan Kesehatan Kerja, dapat membantu mengembangkan presepsi karyawan mengenai pentingnya implementasi Keselamatan dan Kesehatan Kerja. Sehingga karyawan cenderung untuk mematuhi peraturan keselamatan dan berpartisipasi aktif dalam setiap program Keselamatan dan Kesehatan Kerja perusahaan (Mullen, 2005)

\section{Teori Keselamatan dan Kesehatan Kerja Rumah Sakit (K3RS)}

Menurut Keputusan Menteri Kesehatan No. 432 Tahun 2007 tentang Pedoman Manajemen Keselamatan dan Kesehatan Kerja (K3) di Rumah Sakit menyatakan bahwa: "Keselamatan dan Kesehatan Kerja adalah upaya untuk memberikan jaminan keselamatan dan meningkatkan derajat kesehatan para pekerja/buruh dengan cara pencegahan kecelakaan dan penyakit akibat kerja, pengendalian bahaya di tempat kerja, promosi kesehatan, pengobatan dan rehabilitasi".

Menurut Pasal 1 Peraraturan Menteri Kesehatan No. 66 Tahun 2016 tentang Keselamatan dan Kesehatan Kerja di Rumah Sakit, bahwa: "Rumah Sakit adalah institusi pelayanan kesehatan yang menyelenggarakan pelayanan kesehatan perorangan secara paripurna yang menyediakan pelayanan rawat inap, rawat jalan, dan gawat darurat". Serta "Keselamatan dan Kesehatan Kerja Rumah Sakit yang selanjutnya disingkat K3RS adalah segala kegiatan untuk menjamin dan melindungi keselamatan dan kesehatan bagi sumber daya manusia rumah sakit, pasien, pendamping pasien, pengunjung, maupun lingkungan rumah sakit melalui upaya pencegahan kecelakan kerja dan penyakit akibat kerja di rumah sakit."

Berdasarkan Keputusan Menteri Kesehatan No. 432 Tahun 2007 tentang Pedoman Manajemen Keselamatan dan 
Kesehatan Kerja di Rumah Sakit, tujuan keselamatan dan kesehatan kerja Rumah Sakit (K3RS) adalah agar terciptanya cara kerja dan lingkungan kerja yang sehat, aman, nyaman dan dalam rangka meningkatkan derajat kesehatan karyawan Rumah Sakit. Menurut Keputusan Menteri Kesehatan No. 432 Tahun 2007 tentang Pedoman Manajemen Keselamatan dan Kesehatan Kerja di Rumah Sakit, menyatakan bahwa upaya Keselamatan dan Kesehatan Kerja di Rumah Sakit menyangkut tenaga kerja, cara/metode kerja, alat kerja, proses kerja dan lingkungan kerja. Upaya ini meliputi peningkatan, pencegahan, pengobatan dan pemulihan.

Hipotesis:

$\mathrm{H}_{1}$ : terdapat pengaruh parsial partisipasi karyawan terhadap kinerja keselamatan dan kesehatan kerja rumah sakit (K3RS) Santo Borromeus.

$\mathrm{H}_{2}$ : terdapat pengaruh parsial jenis kecelakaan kerja terhadap posisi jabatan karyawan Rumah Sakit Santo Borromeus.

\section{Metode Penelitian}

Jenis penelitian yang digunakan adalah penelitian survey, dimana dalam penelitian ini peneliti menggunakan populasi dan sampel tertentu yang didukung dengan penyebaran kuesioner sebagai alat pengumpulan data (Sekaran, 2014). Metode penelitian yang digunakan dalam penelitian ini adalah mix method, yaitu penelitian yang memadukan atau mengkombinasikan pendekatan penelitian kualitatif dan kuantitatif (Sekaran, 2014).Terdapat dua model penelitian yaitu partisipasi karyawan sebagai variabel Independen (X) serta kinerja keselamatan dan kesehatan kerja Rumah Sakit (K3RS) Santo Borromeus sebagai variabel dependen (Y).

Penelitian ini dilakukan di Rumah Sakit Santo Borromeus, dan dibatasi hanya karyawan pada unit bagian Laboratorium dan unit bagian CSSD sebagai responden penelitian. Populasi dan sampel yang digunakan dalam penelitian ini adalah seluruh karyawan pada unit bagian Laboratorium dan unit bagian CSSD Rumah Sakit Santo Borromeus yaitu sebanyak 50 responden. Teknik pengumpulan data yang digunakan dalam penelitian ini adalah teknik field research (riset lapangan), yaitu dengan melakukan penelitian langsung kepada subjek yang diteliti, untuk memperoleh data primer sebagai bahan yang akan dianalisis, seperti wawancara, observasi, kuesioner, dan studi dokumen.

\section{Operasional Variabel}

\section{Tabel 1}

Operasional Variabel Partisipasi Karyawan

\begin{tabular}{|c|c|c|c|}
\hline Vanbel & Definisi & Indikator & Skala \\
\hline $\begin{array}{l}\text { Partisipasi } \\
\text { Karyaman }\end{array}$ & 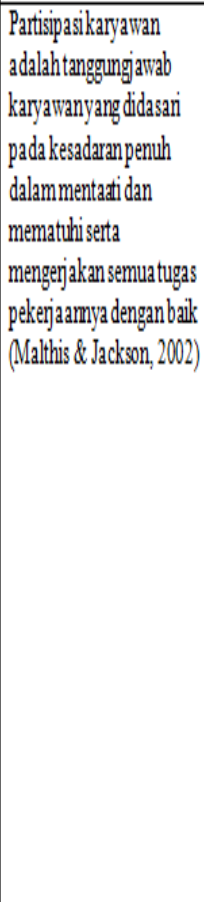 & 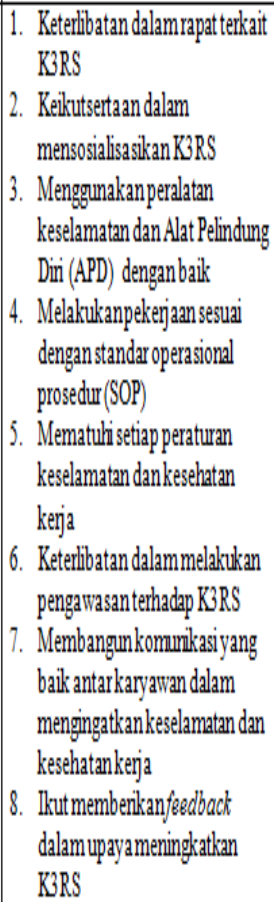 & Ordinal \\
\hline
\end{tabular}


Tabel 2

Operasional Variabel K3RS

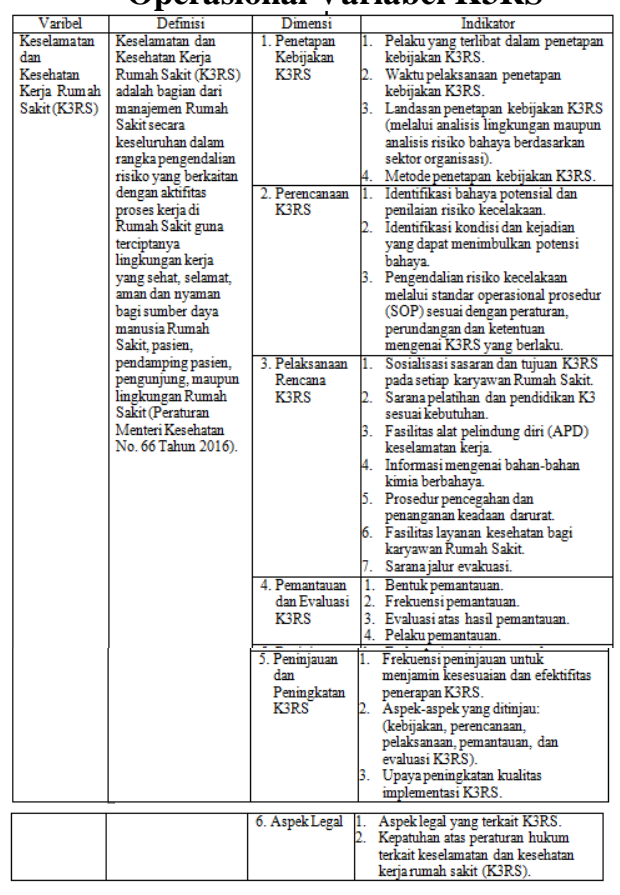

\section{Metode Analisis Data}

Teknik analisis data yang digunakan adalah analisis deskriftif, terhadap seluruh pengujian hipotesis terkait pengaruh partisispasi karyawan terhadap kinerja keselamatan dan kesehatan kerja Rumah Sakit (K3RS) Santo Borromeus. Penelitian ini dilakukan dengan tujuan untuk mengetahui pengaruh antara variabel independen (X) yaitu partisipasi karyawan, terhadap variabel dependen (Y) yaitukinerja keselamatan dan kesehatan kerja Rumah Sakit (K3RS) Santo Borromeus. Melalui analisis korelasi, analisis jalur (path analysis), uji koefisien determinasi $\left(\mathrm{R}^{2}\right)$, uji signifikansi parsial (t-test) dengan tingkat signifikasi 5\%, dan analisis korelasi matriks.

\section{Hasil Penelitian dan Pembahasan}

Hipotesis konseptual yang diajukan adalah diduga adanya pengaruh dari partisipasi karyawan terhadap kinerja keselamatan dan kesehatan kerja Rumah Sakit Santo Borromeus. Metode statistik yang digunakan untuk menguji hipotesis konseptual tersebut adalah path analysis, dengan bentuk persamaan struktural sebagai berikut:

$\mathrm{Y}=\rho \mathrm{YX}+\varepsilon_{2}$

Keterangan:

$\mathrm{Y}=$ Kinerja Keselamatan dan Kesehatan Kerja Rumah Sakit Santo Borromeus

$\mathrm{X}=$ Partisipasi Karyawan

$\rho Y X=$ Koefisien jalur Partisipasi Karyawan terhadap Kinerja Keselamatan dan Kesehatan Kerja Rumah Sakit Santo Borromeus

$\varepsilon \quad=$ Epsilon (pengaruh faktor lain)

\section{Hasil Analisis Korelasi}

Analisis korelasi dilakukan untuk mengetahui bagaimana tingkat keeratan hubungan antara partisipasi karyawan terhadap kinerja keselamatan dan kesehatan kerja Rumah Sakit Santo Borromeus, melalui koefisien korelasi sebagai berikut:

Tabel 3

Interpretasi Koefisien Korelasi

\begin{tabular}{||c|c|}
\hline Interval Korelasi & Tingkat Hubungan \\
\hline \hline $0,00-0,199$ & Sangat Lemah \\
\hline $0,20-0,399$ & Lemah \\
\hline $0,40-0,599$ & Cukup Kuat \\
\hline $0,60-0,799$ & Kuat \\
\hline $0,80-1,000$ & Sangat Kuat \\
\hline
\end{tabular}

Sumber: Sugiyono, (2013: 250)

Berikut adalah tabel hasil perhitungan korelasi antara partisipasi karyawan terhadap kinerja keselamatan dan kesehatan kerja Rumah Sakit Santo Borromeus: 
Tabel 4

Korelasi

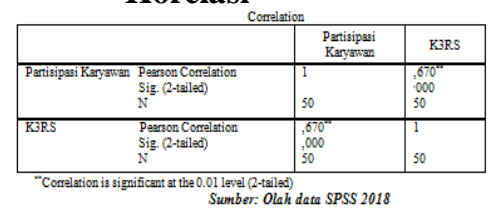

Pada tabel di atas, dapat dilihat bahwa koefisien korelasi antara partisipasi karyawan terhadap kinerja keselamatan dan kesehatan kerja Rumah Sakit adalah sebesar 0,670 dan termasuk dalam kategori hubungan yang kuat, karena berada pada interval korelasi antara 0,60 - 0,799. Koefisien korelasi bertanda positif yang menunjukan hubungan yang terjadi antara keduanya adalah searah, artinya semakin baik partisipasi karyawan, maka kinerja keselamatan dan kesehatan kerja Rumah Sakit akan meningkat. Berdasarkan hasil tersebut, dapat disimpulkan terdapat pengaruh yang kuat antara partisipasi karyawan dengan kinerja keselamatan dan kesehatan kerja Rumah Sakit Santo Borromeus.

2. Hasil Analisis Jalur (Path Analysis) dan Uji Koefisien Determinasi

koefisien jalur $(\rho)$ dan koefisien determinasi pengaruh antara partisipasi karyawan terhadap kinerja keselamatan dan kesehatan kerja Rumah Sakit (K3RS) Santo Borromeus. Menggunakan pengolahan data program SPSS 21.0, yang dapat dilihat pada tabel berikut:

Tabel 5 Koefisien Jalur Partsisipasi Karyawan terhadap K3RS

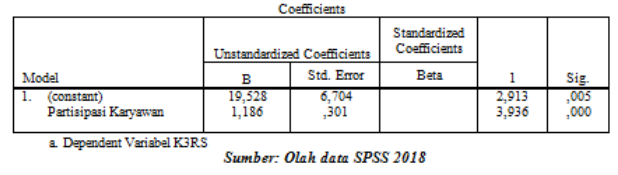

Pada Tabel di atas, dapat dilihat koefisian jalur untuk partisipasi karyawan ( $\rho y x)$ adalah sebesar 0,465. Adapun besar kontribusi koefisien determinasi pengaruh yang diberikan dapat dilakukan dengan menggunakan formula Beta $\mathrm{x}$ Zero Order, yang dapat dilihat pada tabel berikut:

Tabel 6 Koefisien Determinasi Parsial

Coefficients $^{a}$

\begin{tabular}{|c|c|c|c|}
\hline \multirow{2}{*}{\multicolumn{2}{|c|}{ Model }} & $\begin{array}{c}\text { Standardized } \\
\text { Coefficients }\end{array}$ & Correlations \\
\hline & & Beta & Zero-order \\
\hline \multirow[t]{2}{*}{1} & Komitmen Pemimipin & 371 & ,628 \\
\hline & Partisipasi Karyawan & 465 &, 670 \\
\hline
\end{tabular}

Sumber: Olah data SPSS 2018

Pada tabel di atas, pengaruh partisispasi karyawan terhadap kinerja keselamatan dan kesehatan kerja Rumah Sakit Santo Borromeus yaitu = $0,465 \times 0,670=0,312$ atau $31,2 \%$. Maka berdasarkan hasil perhitungan, bahwa partisipasi karyawan memberikan kontribusi pengaruh sebesar $31,2 \%$ terhadap kinerja keselamatan dan kesehatan kerja Rumah Sakit Santo Borromeus.

\section{Hasil Uji Parsial (t-test)}

Pengujian hipotesis parsial pengaruh partisipasi karyawan terhadap kinerja keselamatan dan kesehatan kerja Rumah Sakit (K3RS) Santo Borromeus, dengan rumusan hipotesis parsial sebagai berikut: 


$\begin{array}{rlr}\mathrm{H}_{0}: \rho \mathrm{yx} \leq 0 & \begin{array}{l}\text { Partisipasi } \\ \text { tidak }\end{array} & \begin{array}{r}\text { karyawan } \\ \text { berpengaruh }\end{array} \\ & \text { signifikan } & \text { terhadap } \\ & \text { kinerja keselamatan dan } \\ & \text { kesehatan kerja } & \text { Rumah } \\ & \text { Sakit Santo Borromeus. } \\ \mathrm{H}_{1}: \rho \mathrm{yx}>0 & \text { Partisipasi } & \text { karyawan } \\ & \text { berpengaruh } & \text { signifikan } \\ & \text { terhadap } & \text { kinerja } \\ & \text { keselamatan } & \text { dan } \\ & \text { kesehatan kerja Rumah }\end{array}$

Taraf signifikansi $\quad(\alpha) \quad$ yang digunakan sebesar 5\%.

Kriteria pengambilan keputusan uji parsial:

1) Tolak $\mathrm{H}_{0}$ dan terima $\mathrm{H}_{1}$ jika nilai $\mathrm{t}_{\text {hitung }}>\mathrm{t}_{\text {tabel }} /-\mathrm{t}_{\text {hitung }}<-\mathrm{t}_{\text {tabel }}$

2) Terima $\mathrm{H}_{0}$ dan tolak $\mathrm{H}_{1}$ jika nilai $t_{\text {hitung }}<t_{\text {tabel }} /-t_{\text {hitung }}>-t_{\text {tabel }}$

Metode statistik yang digunakan untuk menguji hipotesis parsial ini adalah uji $t$. Nilai $\mathrm{t}_{\text {tabel }}$ yang digunakan sebagai nilai kritis dalam uji $\mathrm{t}$ ini adalah sebesar 2,012 yang diperoleh dari tabel distribusi t dengan a 5\% dan df (n(50)-k(2)-1) 47 untuk uji dua pihak. Rangkuman hasil pengujian disajikan pada tabel berikut:

\begin{tabular}{|c|c|c|c|c|c|c|}
\hline Model & $t_{\text {than }}$ & $t_{\text {stad }}$ & Sig. & $\alpha$ & Keterangan & Kesimpulan \\
\hline $\mathrm{X}_{2} \rightarrow \mathrm{Y}$ & 3,936 & 2,012 & 0,000 & 0,05 & $\mathrm{H}_{0}$ ditolak & Signifikan \\
\hline \multicolumn{6}{|c|}{ Sumber: Olah data SPSS 2018}
\end{tabular}

Secara visual, daerah penolakan $\mathrm{H}_{0}$ maupun penerimaan $\mathrm{H}_{0}$ digambarkan sebagai berikut:

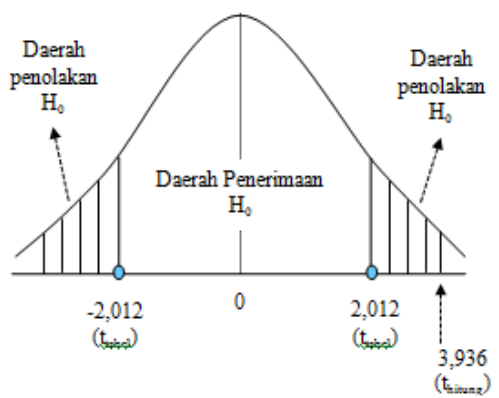

Gambar Kurva Hipotesis Parsial Pengaruh Partisipasi Karyawan Terhadap Kinerja Keselamatan dan

\section{Kesehatan Kerja Rumah Sakit Santo Borromeus}

Pada gambar kurva hipotesis parsial 4.16 di atas, dapat dilihat nilai $t_{\text {hitung sebesar 3,936 ada didaerah }}$ penolakan $\mathrm{H}_{0}$, maka dengan tingkat kepercayaan $95 \%$ diputuskan untuk menolak $\mathrm{H}_{0}$ dan menerima $\mathrm{H}_{1}$. Hasil tersebut menunjukan bahwa partisipasi karyawan berpengaruh signifikan terhadap kinerja keselamatan dan kesehatan kerja Rumah SakitSanto Borromeus.

\section{Hasil Korelasi Matriks}

Rumah Sakit Santo Borromeus masih memiliki kasus kecelakaan kerja yang cukup tinggi yaitu sebesar 36\%. Dengan jenis kecelakaan terbanyak adalah jenis kecelakaan tertusuk jarum yaitu sebanyak 24\%. Angka tersebut diperoleh dari hasil kuesioner pada responden karyawan unit bagian Laboratorium dan unit bagian CSSD. Dalam hal ini peneliti tertarik untuk melihat apakah terdapat pengaruh jenis kecelakaan kerja terhadap posisi jabatan karyawan. Berikut adalah tabulasi silang antara jenis kecelakaan kerja terhadap posisi jabatan karyawan Rumah Sakit Santo Borromeus:

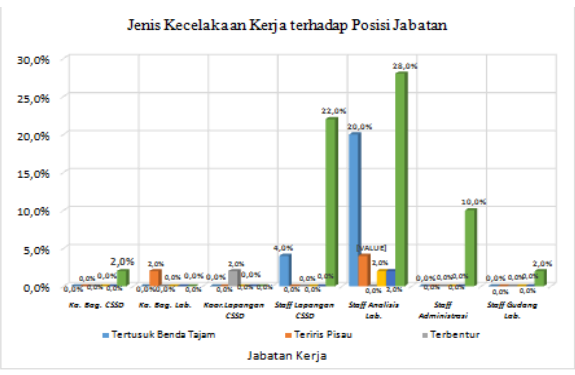

\section{Grafik Tabulasi Silang antara Jenis \\ Kecelakaan Kerja terhadap Posisi Jabatan}

Sumber: Olah data SPSS 2018 
Berdasarkan grafik diatas dapat dilihat bahwa karyawan yang seringkali mengalami kecelakaan kerja tertusuk benda tajam adalah staff analisis laboratorium. Jenis kecelakaan kerja tertusuk benda tajam diklasifikasikan kedalam dua jenis yaitu tertusuk jarum dan tertusuk benda tajam lainnya. Berdasarkan hasil analisis korelasi, jenis kecelakaan kerja memiliki hubungan yang signifikan terhadap posisi jabatan, hal ini dibuktikan dengan nilai signifikan < 0,05 , yang dapat dilihat pada tabel dibawah ini:

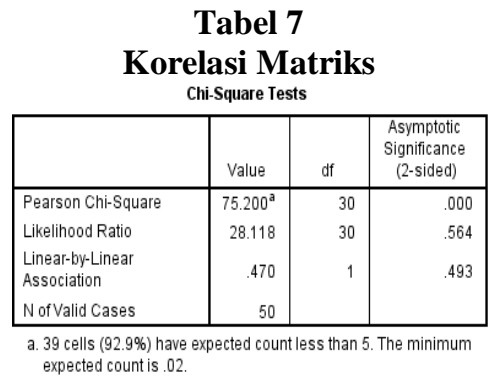

\section{Sumber: Olah data SPSS 2018}

Berdasarkan hasil pengolahan data, dapat disimpulkan bahwa posisi pekerjaan tertentu dengan potensi risiko bahaya yang tinggi memiliki potensi kecelakaan kerja yang lebih besar. Sebaliknya jika posisi pekerjaan karyawan tidak memiliki potensi bahaya yang tinggi, maka potensi terjadinya kecelakaan kerja pada karyawan juga dapat dikatakan rendah.

\section{Simpulan dan Saran}

\section{Simpulan}

Berdasarkan dari hasil analisis penelitian terkait pengaruh partisipasi karyawan terhadap kinerja keselamatan dan kesehatan kerja Rumah Sakit Santo Borromeus, peneliti dapat menarik beberapa kesimpulan sebagai berikut:
1. Partisipasi karyawan memberikan kontribusi pengaruh sebesar 31,2\% terhadap kinerja keselamatan dan kesehatan kerja Rumah Sakit Santo Borromeus. Karena pada dasarnya, kinerja keselamatan dan kesehatan kerja yang efektif bergantung pada faktor manusia itu sendiri. Dengan kata lain, keselamatan dan kesehatan kerja yang efektif tidak terlepas dari keterlibatan aktif karyawan dalam upayan meningkatkan kinerja keselamatan dan kesehatan kerja di Rumah Sakit Santo Borromeus. Kinerja keselamatan dan kesehatan kerja Rumah Sakit Santo Borromeus dapat meningkat jika partisipasi karyawan terhadap keselamatan dan kesehatan kerja juga baik. Oleh karena itu, Rumah Sakit Santo Borromeus harus dapat memperbaiki dan meningkatkan kesadaran karyawan terkait keselamatan dan kesehatan di tempat kerja. Sehingga karyawan dapat berpartisipasi aktif dalam mendukung kinerja keselamatan dan kesehatan kerja Rumah Sakit.

2. Jenis kecelakaan kerja mempunyai pengaruh yang signifikan terhadap posisi jabatan karyawan Rumah Sakit Santo Borromeus. Hal tersebut menunjukkan bahwa karyawan yang mempunyai posisi pekerjaan tertentu dengan potensi risiko bahaya yang tinggi memiliki potensi kecelakaan kerja yang lebih besar. Dalam hal ini, karena sebagian besar responden kuesioner adalah staff analisis laboratorium maka dapat dikatakan bahwa memang jenis kecelakaan kerja mempunyai pengaruh signifikan terhadap posisi jabatan, karena hanya staff laboratorium yang memiliki risiko kecelakaan kerja tertusuk jarum yang tinggi, karena staff analisis laboratorium yang sering berhubungan dengan penggunaan jarum suntik. 


\section{Saran}

1. Meningkatkan pembinaan karyawan dalam upaya meningkatkan partisipasi karyawan terhadap keselamatan dan kesehatan kerja di Rumah Sakit. Dalam hal ini, partisipasi karyawan terkait kesadaran akan pentingnya keselamatan dan kesehatan di tempat kerja masih kurang. Peneliti menganggap bahwa sebagaian besar karyawan Rumah Sakit Santo Borromeus khususnya karyawan pada unit bagian Laboratorium dan unit bagian CSSD masih memiliki kepedulian yang rendah terkait K3RS. Seperti kepedulian dalam mengunakan Alat Pelindung Diri (APD) secara lengkap sesui dengan kebutuhan pekerjaan. Karena penggunaan APD yang baik dan lengkap dapat meminimalisir terjadinya kecelakaan kerja yang diakibatkan oleh berbagai risiko potensial pekerjaan.

2. Angka kecelakaan kerja pada Rumah Sakit Santo Borromeus masih cukup tinggai, yaitu sebesar 24\%. Sehingga Rumah Sakit Santo Borromeus perlu untuk meningkatkan pengawasaan terkait cara kerja dan perilaku kerja karyawan yang dapat meningkatkan potensi kecelakaan kerja seperti bekerja tidak sesuai SOP atau ketidak hatihatian karyawan dalam bekerja, sehingga meningkatkan potensi kecelakaan kerja.

\section{Daftar Pustaka}

Akpan, E. I. (2011). Effective Safety and Health Management Policy for Improved Performance of Organizations in Africa. International Journal of Business and Management Vol. 6, No. 3.
Amstrong, M. (2006). A Handbook of Human Resources Management Practice Edition. London: Kogan Page.

Dewi, A. A. (2006). Analisis Beberapa Faktor yang Mempengaruhi Partisipasi Karyawan. Buletin Studi Ekonomi Volume 11 Nomor 1 ISSN1410-4628.

Hasibuan, M. (2005). Manajemen Sumber Daya Manusia. Jakarta: Bumi Aksara.

Lyon, B. (2005). Health \& Safety Management Systems: Focus on Management. Occupational Hazards, 45.

Mullen, J. (2005). Safety-specific Transformational Leadership: An Experimental Study. Canada: Saint Mary's University.

Sekaran, U. (2014). Research Method For Business Edisi 4. Jakarta: Salemba Empat.

Smith, S. (1994). The right chemistry for safety. Occupational Hazards, 37.

Sugiyono. (2013). Metode Penelitian Bisnis. Bandung: Alfabeta.

Tint, P. (2006). Auditing of Safety Management System in Estonian Medium-Scale Enterprises. Symposium Series No. 151.

Zubbar, A. (2014). Occupational Health and Safety Management in Manufacturing Industries. Journal of Scientific \& Industrial Research Vol 73, 381-386.

\section{Referensi Peraturan Legal}

Undang-Undang Nomor 13 Tahun 2003 tentang Ketenagakerjaan

Undang-Undang Nomor 1 Tahin 1970 tentang Keselamatan Kerja

Undang-Undang Nomor 36 Tahun 2009 tentang Kesehatan 
Jurnal Akuntansi Maranathan Volume 10 Nomor 2, November 2018 : 212-222

Undang-Undang Nomor 36 Tahun 2014 tentang Tenaga Kesehatan

Peraturan Pemerintah Republik Indonesia Nomor 50 Tahun 2012 tentang Penerapan Sistem Manajemen Keselamatan dan Kesehatan Kerja

Keputusan Menteri Kesehatan Nomor 432 Tahun 2007 tentang Pedoman Manajemen Keselamatan dan Kesehatan Kerja di Rumah Sakit

Peraturan Menteri Kesehatan Nomor 66 Tahun 2016 tentang Keselamatan dan Kesehatan Kerja di Rumah Sakit

Peraturan Menteri Kesehatan Nomor 27 Tahun 2017 tentang Pedoman Pencegahan dan Pengendalian Infeksi

Peraturan Menteri Kesehatan Nomor 411 Tahun 2010 tentang Laboratorium Klinik

\section{Referensi Internet}

https://www.bps.go.id/website/pdf_publikas i/Laporan-Bulanan-Data-SosialEkonomi-November-2017.pdf

https://www.bps.go.id/linkTabelStatis/view/i $d / 96$ 